\title{
Infrared Video Thermometry Guidance for Surgical Correction of Chylothorax in Dogs
}

\author{
Mariana da Silva Ribeiro, Marcelo Borges dos Santos Junior, Marina Tomaz Gonçalves de Moraes, \\ Paula Gebe Abreu Cabral, Fernanda Antunes \& André Lacerda de Abreu Oliveira
}

\begin{abstract}
Background: Macroscopic identification of the extravasation site of chyle in patients with chylothorax is a major challenge. Current forms of identification are invasive and/or expose patients to radiation, as in computerized tomography and radiography. A prototype device that uses infrared video thermometry images to detect temperature increments of $0.1^{\circ} \mathrm{C}$ has been developed. This device can process and show real-time images or video on a monitor during surgeries. Therefore, the aim of this work was to report the first successful case in which this innovative device was tested in the transoperative period to identify the thoracic duct and its tributaries in a chylothorax surgery performed in a dog.

Case: A 2-year-old male dog of the Shiba Inu breed was presented to the veterinary hospital with exercise intolerance, cough, emaciation, and no history of trauma. Clinical examination was performed along with complete blood count, biochemical analysis, and thoracic radiography. The patient exhibited dyspnea and had diminished breath sounds on chest auscultation. Radiographic images revealed moderate pleural effusion. The dog was anesthetized and submitted to thoracotomy, which enabled visualization of a chylous effusion. A sample of the effusion was collected for cytological and biochemical analyses. Subsequently, pericardiectomy was carried out, and identification of the thoracic duct and its tributaries was guided by an innovative device that generates infrared video thermometry images in real time. The extravasation site of the chyle was visualized on the images shown on a monitor. Consequently, after ligation of the tributary vessel, interruption of chyle overflow could be noticed on the monitor. Thoracotomy was routinely closed, and a drain was placed through an intercostal space after incision. Thirty days after the surgery, the dog exhibited no signs of recurrence. Cytological and biochemical analyses of the effusion revealed an abnormal transudate that had a density of $1,030 \mathrm{~g} / \mathrm{cm}^{3}$, alkaline $\mathrm{pH}$, predominance of neutrophils and lymphocytes, and high levels of proteins, triglycerides and cholesterol. These results indicated that the effusion analyzed was chyle.

Discussion: Macroscopic aspects of an effusion alone should not be used to make a definitive diagnosis; cytological, physi$\mathrm{cal}$, and biochemical evaluations are indispensable. The specimen analyzed had a higher concentration of triglycerides than blood, and its cholesterol concentration was lower than that found in blood. Findings like these have already been reported as indicative of chylous effusion. Thoracic duct ligation is the most used technique for correction of chylothorax, and is the technique with better outcomes. Thermometry has already been used for clinical examination in several diseases. However, the innovative device used in this study has the advantage of being noninvasive, and was able to guide the surgeon during the surgery to locate the thoracic duct and precisely identify the tributary lymphatic vessel responsible for the chylous effusion. The physical space occupied by the device did not disturb the surgical team since a small infrared image generator was placed one meter above the patient to take high definition images of the entire animal in the evaluation field. The thermometry device was very useful, non-invasive, and precise to differentiate thoracic structures and to identify the site of extravasation of chyle. It also allowed a more interactive and precise surgical approach by the surgical team, which was essential to the success of the surgery.
\end{abstract}

Keywords: chyle extravasation, infrared diagnosis, surgery, thorax. 


\section{INTRODUCTION}

Accumulation of chyle in the chest is infrequent, and occurs when there is extravasation of chyle from the thoracic duct or its tributaries; ligation of these structures is the most common procedure used as a surgical treatment. However, the macroscopic identification of the extravasation site is always a great challenge for the surgical team. The most common forms of identification of the extravasation site are radiographic or tomographic examination using contrast media at the preoperative period $[4,10]$.

Currently, there is no non-invasive method to assist the surgical team in identifying the extravasation point during the surgery without previously subjecting the patient to radiation-based diagnosis. Infrared thermometry has proved to be effective for the diagnosis of various pathologic processes [6].

A prototype device that uses infrared thermometry technology was developed to provide real-time images that can be used to detect metabolic activity patterns. This is the first report of successful trans-operative use of this device to identify the thoracic duct for the correction of chylothorax in a dog.

\section{CASE}

A 2-year-old male Shiba Inu dog weighing $10.8 \mathrm{~kg}$ was referred to veterinary hospital after being diagnosed with chylothorax. At the first appointment, the patient exhibited exercise intolerance, cough, and emaciation, with no previous history of trauma. During clinical examination, the patient was alert and responsive; however, it was dyspneic, had difficulty inhaling, and exhibited a prolonged expiration. Breath sounds on chest auscultation were diminished.

Pre-operative blood tests revealed neutrophilia, lymphopenia, and increased alanine aminotransferase levels (109 UI/L). Erythrogram, platelets, urea, creatinine and alkaline phosphatase levels were within the normal ranges. Thoracic radiography showed thickening of interlobar fissures and lung retraction that were compatible with moderate pleural effusion.

A prototype equipment called MART (Metabolic Activity in Real Time - FLIR SC $\left.325^{\circledR}\right)^{1}$ was used for the acquisition of infrared video thermometry images. The equipment also included an edit bay coupled to an infrared generator. An infrared camera was positioned one meter above the patient, which provided a field of view that covered the entire operative field.
Set up in this way, the camera could detect temperature variations of $0.1^{\circ} \mathrm{C}$. Besides acquiring images, this imaging system could process and display real-time images or videos on a monitor. The system's ability of generating real-time images enabled the surgical team to perform a more interactive and precise surgical approach.

Premedication consisted of chlorpromazine $\left(\text { Clorpromaz }^{\circledR}\right)^{2}\left[1.1 \mathrm{mg} \cdot \mathrm{kg}^{-1}\right]$ and morphine (Dimorf $\left.{ }^{\circledR}\right)^{3}\left[0.1 \mathrm{mg} \cdot \mathrm{kg}^{-1}\right]$, both intramuscular. Then, the patient was induced with ketamine $\left(\text { Quetamina }{ }^{\circledR}\right)^{4}[10$ $\left.\mathrm{mg} \cdot \mathrm{kg}^{-1}\right]$ and midazolam $\left(\text { Dormire }{ }^{\circledR}\right)^{5}\left[0.2 \mathrm{mg} \cdot \mathrm{kg}^{-1}\right]$, which were administered intravenously. Anesthesia was maintained with isoflurane (Isoforine $\left.{ }^{\circledR}\right)^{3}$ until the end of surgery.

The surgery was carried out with the patient in right lateral decubitus after antisepsis with povidoneiodine $\left(\text { Riodine }^{\circledR}\right)^{5}$ and $70 \%$ alcohol $\left(\text { Rialcool } 70^{\circledR}\right)^{5}$. A left thoracotomy was done in the fifth intercostal space. After opening the thorax, a chylous effusion was found (Figure 1), and a sample of it was collected for further analysis. The effusion was completely suctioned, and then a subtotal pericardiectomy was performed.

The MART device was coupled to a television in front of the surgical team, allowing detection of the thoracic duct and its tributaries, which were responsible for chylous effusion. To confirm detection of the leaking site, the equipment was used to guide the surgeon to temporarily occlude a tributary vessel with an atraumatic clamp. When the vessel was occluded, further extravasation of chyle could not be observed (Figure 2A). However, after releasing the clamp, the surgical team visualized the chylous effusion again (Figure 2B). Subsequently, the surgeon dissected the tributary vessel and made a ligature with 3-0 nylon (Mononylon $\left.{ }^{\circledR}\right)^{6}$ [Figure 3].

Before closure of the thorax, a thoracic drain $\left(\text { Medidren }{ }^{\circledR}\right)^{7}$ was placed through an intercostal space caudal to the incision. The thoracotomy was closed with three interrupted sutures around the ribs using nylon $0^{6}$. Then, muscles, subcutaneous tissue, and skin were routinely closed.

Postoperative therapy consisted of amoxicillinclavulanate (Agemoxi CL $\left.{ }^{\circledR}\right)^{8}$ [25 mg. $\mathrm{kg}^{-1}, \mathrm{BID}$, orally] for 15 days and firocoxib (Previcox $\left.{ }^{\circledR}\right)^{9}\left[5 \mathrm{mg} \cdot \mathrm{kg}^{-1}, \mathrm{SID}\right.$, orally] for 10 days. A balanced post-operative analgesia was done with a solution containing midazolam, lidocaine $\left(\text { Lidovet }^{\circledR}\right)^{10}$ and ketamine in continuous infusion during three days, as suggested by Lukasik [7]. There 
was no complication associated with this procedure. Thirty days after the surgery, the dog exhibited no signs of recurrence.

Analysis of the effusion sample collected during surgery reveled a modified transudate with milky appearance, $1,030 \mathrm{~g} / \mathrm{cm}^{3}$ of density, neutral $\mathrm{pH}$ (7.0) and many sediments. Laboratory findings included high protein concentration, presence of glucose, hemoglobin, and leucocytes. There were 4,200 nucleated cells $/ \mu \mathrm{L}$, with predominance of neutrophils and lymphocytes. Eosinophils, mesothelial cells, monocytes, and red blood cells were also present. The concentration of triglycerides $(10,310 \mathrm{mg} / \mathrm{L})$ found in the sample was higher than that found in the blood (450 mg/L). Whereas, the concentration of cholesterol was lower $(1,000 \mathrm{mg} / \mathrm{L})$ in the chylous specimen than in the blood $(1,830 \mathrm{mg} / \mathrm{L})$.

\section{DISCUSSION}

Chylous effusion has a characteristic milky appearance; however, macroscopic aspects alone must not be used to make a definitive diagnosis, as cytological, physical, and biochemical evaluation of the specimen are indispensable. In the present case, besides milky appearance fluid, the chylous specimen analyzed contained a triglyceride concentration more than 20-fold higher than that found in the blood. Additionally, the concentration of cholesterol in the effusion sample was lower than that found in the blood. These two findings have been reported as normal in chylous effusions [9].

As reported in the literature, chronic cases of chylothorax can result in several issues, including hypoproteinemia, immunodeficiency, dehydration, and weight loss. Therefore, surgical correction of chylothorax is highly recommended. The technique that is most widely used and that provides the best outcomes for this condition is ligation of the thoracic duct $[2,5,9,10]$.

The biggest challenge in thoracic duct ligation is finding the duct, which is not always visible. In order to improve surgical results, some techniques are reported to highlight this vessel, such as injection of methylene blue directly into a mesenteric or caudal peripheral lymph node, feeding heavy table cream to the patient one hour before surgery, or injection of indocyanine green followed by illumination with near-infrared light $[1,3,9]$. In the present case, we used an innovative device to help us find the thoracic duct;

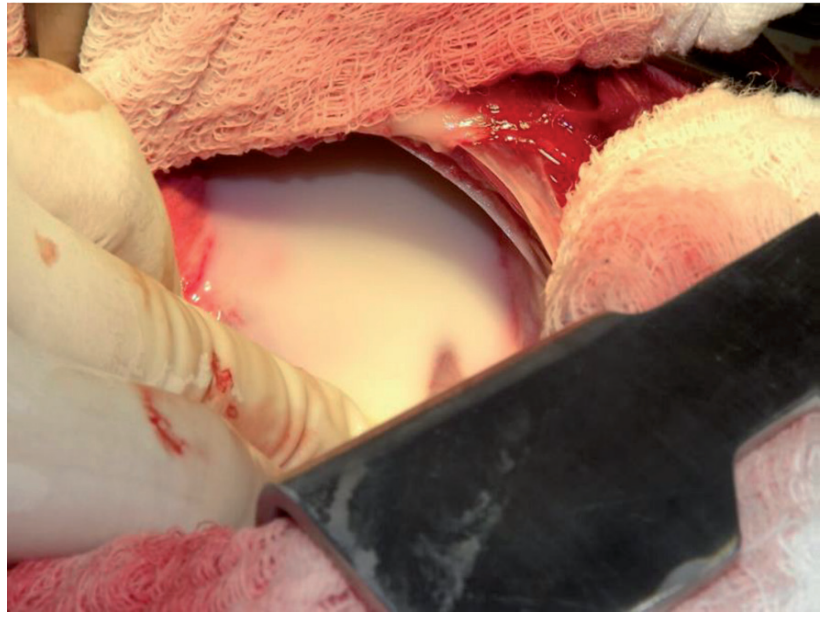

Figure 1. Chylothorax in a dog. Visualization of chylous effusion after thoracotomy.

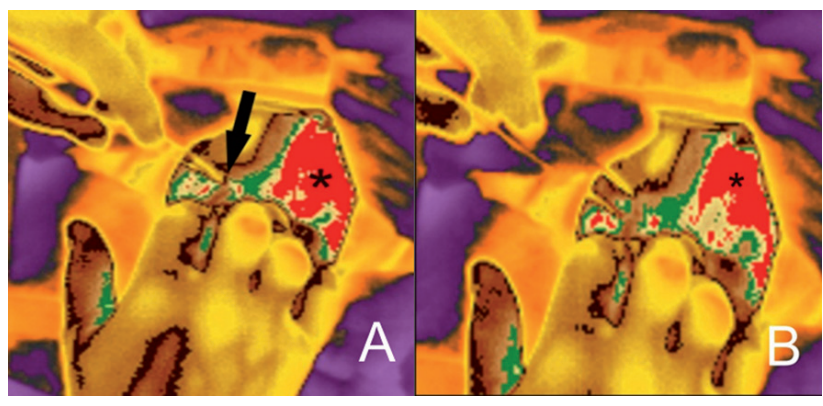

Figure 2. Infrared images obtained using the MART (Metabolic Activity in Real Time) equipment after thoracotomy. A- Interruption of chylous effusion (asterisk) after temporary occlusion of the tributary lymphatic vessel (arrow). B- Increased volume of chylous effusion (arrow) after release of the vascular clamp. The thoracic duct (upper white arrow) and a thoracic duct's tributary (bottom white arrow) can also be identified.

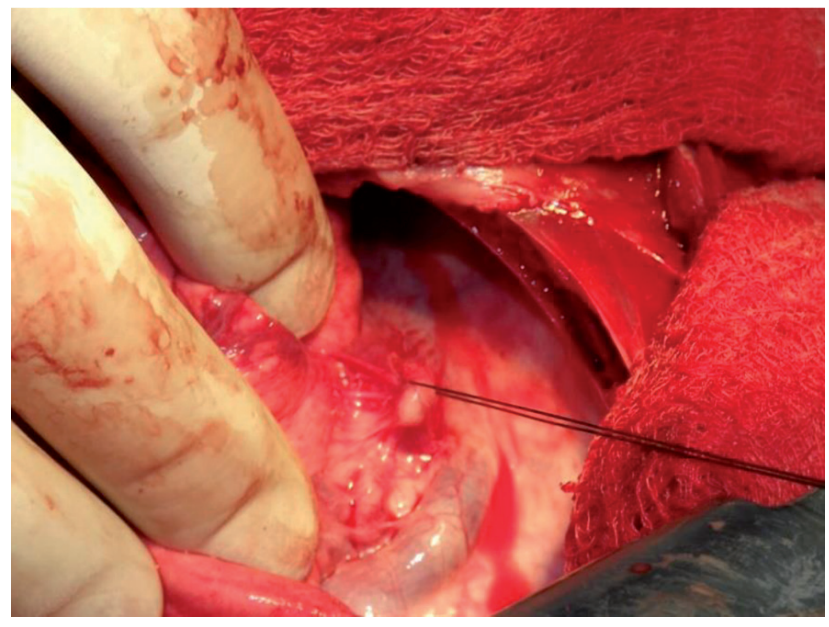

Figure 3. Surgical correction of chylothorax in a dog. Ligation of the thoracic duct's tributary. Note that it was possible to perfectly locate the duct using MART guidance.

this procedure allowed the surgical team to precisely locate the tributary lymphatic vessel responsible for chyle leakage.

Thermometry has already been used for the diagnosis of several diseases, including breast cancer in humans and lameness in dairy cattle, owing to its capability of highlighting areas with different tempera- 
tures, which can be interpreted as areas with different metabolic activity $[6,11,13]$. In the present case, we used the same principle to detect a leaking point in a lymphatic vessel in real time during the surgery, which improved the surgical procedure.

The aim of using the MART device is to provide the surgical team with real-time guidance in several procedures. MART has some advantages when compared to other techniques such as fluoroscopy, which has the advantage of allowing less invasive procedures but has the disadvantage of exposing the surgical team to radiation [12]. The amount of room occupied by the equipment did not disturb the surgical team, since the edit bay was positioned far from the operative field and the small infrared camera used for the acquisition of high definition infrared images was placed one meter above the patient.

In conclusion, the prototype infrared equipment used in this case proved to be a very useful, non-invasive and precise tool to identify the site of extravasation of chyle, which was essential to the success of the surgery.

\section{MANUFACTURERS}

${ }^{1}$ FLIR. Boston, MA, USA.

${ }^{2}$ União Química Farmacêutica Nacional S.A. Embu-Guaçu, SP, Brazil.

${ }^{3}$ Cristália Produtos Químicos e Farmacêuticos Ltda., Itapira, SP, Brazil.

${ }^{4}$ Vetnil Indústria e Comércio de Produtos Veterinários Ltda. Louveira, SP, Brazil.

${ }^{5}$ Rioquímica Indústria Farmacêutica. São José do Rio Preto, SP, Brazil

${ }^{6}$ Ethicon Johnson \& Johnson do Brasil Indústria e Comércio. São Paulo, SP, Brazil.

${ }^{7}$ Cremer S.A. Blumenau, SC, Brazil.

${ }^{8}$ Agener União - Saúde Animal. São Paulo, SP, Brazil.

${ }^{9}$ Merial Limited. Duluth, GA, USA.

${ }^{10}$ Bravet. Rio de Janeiro, RJ, Brazil.

Declaration of interest. The authors report no conflicts of interest. The authors alone are responsible for the content and writing of the paper.

\section{REFERENCES}

1 Allman D.A., Radlinsky M.G., Ralph A.G. \& Rawlings C.A. 2010. Thoracoscopic Thoracic Duct Ligation and Thoracoscopic Pericardectomy for Treatment of Chylothorax in Dogs. Veterinary surgery. (39): 21-27.

2 Carobbi B., White R.A.S. \& Romanelli G. 2008. Treatment of idiopathic chylothorax in 14 dogs by ligation of the thoracic duct and partial pericardiectomy. The Veterinary Record.(163): 743-745.

3 Enwiller T.M., Radlinsky M.G., Mason D.E. \& Roush J.K. 2003. Popliteal and Mesenteric Lymph Node Injection With Methylene Blue for Coloration of the Thoracic Duct in Dogs. Veterinary Surgery. (32): 359-364.

4 Epstein S.E. 2014. Exudative pleural diseases in small animals. Veterinary Clinics: Small Animal Practice. 44(1): 161-180.

5 Fossum T.W., Mertens M.M., Miller M.W., Peacock J.T., Saunders A., Gordon S. \& Hobson P.H. 2004. Thoracic Duct Ligation and Pericardectomy for Treatment of Idiopathic Chylothorax. Journal of veterinary internal medicine. 18(3): 307-310.

6 Lahiri B.B., Bagavathiappan S., Jayakuma T. \& Philip J. 2012. Medical applications of infrared thermography: A review. Infrared Physics \& Technology. 55(4): 221-235.

7 Lukasik V.M. 2014. Balanced post-operative analgesia. In: Symposium Proceedings Technician Lectures. Animal Specialty \& Emergency Center. [Fonte: <http:// http://www.asecvets.com/wp-content/uploads/2014/09/ASEC2014-Balanced-Post-Operative-Analgesia.pdf $>$ ]. [Accessed online in July 2015].

8 Martin R.A., Richards D.L.S., Barber D.L., Cordes D.O. \& Sufit E. 1988. Transdiaphragmatic Approach to Thoracic Duct Ligation in the Cat. Veterinary Surgery. 17(1): 22-26.

9 Singh A., Brisson B. \& Nykamp S. 2012. Idiopathic chylothorax: pathophysiology, diagnosis and thoracic duct imaging. Compendium on Continuing Education for the Practising Veterinarian. 34(8): E2.

10 Singh A., Brisson B. \& Nykamp S. 2012. Idiopathic chylothorax in dogs and cats: nonsurgical and surgical management. Compendium on Continuing Education for the Practising Veterinarian. 34(8): E3. 
M.S. Ribeiro, M.B. Santos Junior, M.T.G. Moraes, et al. 2018. Infrared Video Thermometry Guidance for Surgical Correction of Chylothorax in Dogs. Acta Scientiae Veterinariae. 46(Suppl1): 261.

11 Stokes J.E., Leach K.A., Main D.C.J. \& Whay H.R. 2012. An investigation into the use of infrared thermography (IRT) as a rapid diagnostic tool for foot lesions in dairy cattle. The Veterinary Journal. 193(3): 674-678.

12 Tivers M.S. \& Moore A.H. 2006. Tracheal foreign bodies in the cat and the use of fluoroscopy for removal: 12 cases. Journal of small animal practice. 47(3): 155-159.

13 Wood S., Lin Y., Knowles T.G. \& Main D.C.J. 2015. Infrared thermometry for lesion monitoring in cattle lameness. Veterinary Record. 176, 308. [Fonte: < http://veterinaryrecord.bmj.com/content/vetrec/176/12/308.full.pdf >]. [Accessed online in August 2016]. 